\title{
The Sm-Nd Isotopic Method in the Geochronology Laboratory of the University of Brasília
}

\author{
S.M.C.L. GIOIA and M.M. PIMENTEL* \\ Universidade de Brasília, Instituto de Geociências, \\ Laboratório de Geocronologia, Cx. Postal 04465, 70910-900 Brasília, DF
}

Manuscript received November 3, 1998; accepted for publication on November 9, 1999; contributed by M.M. PIMENTEL

\begin{abstract}
$\mathrm{Nd}$ isotopes represent one of the best tools to investigate the processes involved in the evolution of the continental crust and mantle. This is due mainly to the similar geochemical behaviour of $\mathrm{Sm}$ and $\mathrm{Nd}$, both light rare earth elements, which inhibits their fractionation during most varied geological processes. In order to carry out crustal evolution studies in central Brazil, the Sm-Nd isotopic method was implanted at the Geochronology Laboratory of the University of Brasília. The Sm-Nd separation methodology is basically that described in Richard et al. (1976), with the addition of some improvements. In this study we describe in detail the methodology used in Brasília. Precision and accuracy were checked with the international standards such as JB3, BCR-1, BHVO-1 and La Jolla, and the following results were found: JB-3 ( Nd=15.74 ppm and $\mathrm{Sm}=4.28 \mathrm{ppm}), \mathrm{BCR}-1\left({ }^{143} \mathrm{Nd} /{ }^{144} \mathrm{Nd}=0.512647 \pm 8, \mathrm{Nd}=28.73 \mathrm{ppm}\right.$ and $\left.\mathrm{Sm}=6.66 \mathrm{ppm}\right)$, BHVO-1 $(\mathrm{Nd}=24.83 \mathrm{ppm}$ and $\mathrm{Sm}=6.2 \mathrm{ppm})$ and La Jolla $\left({ }^{143} \mathrm{Nd} /{ }^{144} \mathrm{Nd}=0.511835 \pm 14\right)$.
\end{abstract}

Key words: Sm-Nd method, isotope dilution, ion exchange chromatography, TIMS.

\section{INTRODUCTION}

The Sm-Nd geochronometer is based on the decay of ${ }^{147} \mathrm{Sm}$ to ${ }^{143} \mathrm{Nd}$, with the emission of an $\alpha$ particle. The equation below describes the $\mathrm{Sm}-\mathrm{Nd}$ isotopic evolution for any geological system:

$$
{ }^{143} N d={ }^{143} N d_{i}+{ }^{147} \operatorname{Sm}\left(e^{\lambda t}-1\right){ }^{(1)},
$$

Equation (1) can also be written as:

$$
\frac{{ }^{143} N d}{{ }^{144} N d}=\left(\frac{{ }^{143} N d}{{ }^{144} N d}\right)_{i}+\frac{{ }^{147} S m}{{ }^{144} N d}\left(e^{\lambda t}-1\right)
$$

\footnotetext{
* Member of the Academia Brasileira de Ciências

Correspondence to: S.M.C.L. Gioia

E-mail: sgioia@unb.br
} 
The age $t$ of the system can be calculated after the determination of ${ }^{143} \mathrm{Nd} /{ }^{144} \mathrm{Nd}$ and ${ }^{147} \mathrm{Sm} /{ }^{144} \mathrm{Nd}$ ratios. Thermal Ionisation Mass Spectrometry (TIMS) is the most commonly used technique for the determination of isotopic ratios and also for the determination of REEs concentrations by isotope dilution. The isotopic analysis is the mass spectrometer is preceded by chemical treatment, involving the addition of a spike solution, dissolution of the sample and the chemical extraction of Sm and $\mathrm{Nd}$ by ion exchange. The extraction of $\mathrm{Sm}$ and $\mathrm{Nd}$ are accomplished in two stages. The first stage consists of the bulk separation of lanthanide fraction and in the second stage, the elements are separated from each other in order to avoid isobaric interference and also the presence of elements that make the ion beam unstable or that interfere with the ionisation efficiency of Sm and $\mathrm{Nd}$.

This work reports an efficient method of micro-extraction used for $\mathrm{Sm}$ and $\mathrm{Nd}$ separation, based on the method employed by Richard et al. (1976).

\section{METHODOLOGY}

\section{Summary of Previous Chemical Separation Methods}

Precise and accurate determination of isotopic ratios of metals cannot be achieved if they have not been efficiently separated from other interfering elements. If traces of elements of the matrix are present in the aliquot to be analyzed, isobaric interference can happen (Potts 1987). In the pioneer work of Ketelle \& Boyd (1951), the difficulty to obtain efficient separation of each element of the REE group, was stressed.

The method most commonly applied in the separation of $\mathrm{Sm}$ and $\mathrm{Nd}$ for isotopic analyses of geological samples is described in Richard et al. (1976). It firstly uses an ion exchange column for the REE separation, followed by chromatography of reverse phase in order to separate Sm and $\mathrm{Nd}$. This second column is packed with polytetrafluorethylene powder (PTFE), impregnated with DI-(2-etilexil) phosphoric acid (HDEHP).

This method, however, is not capable of separating Ce and Pr, which are present in substantial amounts in the $\mathrm{Nd}$ fraction (White \& Patchett 1984). The presence of Ce, for instance, can make the ion beam unstable if present in large amounts (Whitehouse 1989). Whitehouse (1989) describes a method capable of reducing the amount of $\mathrm{Ce}$ in the $\mathrm{Nd}$ fraction, oxidating from $\mathrm{Ce}^{3+}$ to $\mathrm{Ce}^{4+}$ with $\mathrm{KBrO}_{3}$ and passing the solution through a HDEHP micro-column of approximately $1 \mathrm{~cm}$. Another method that uses the classic ion exchange chromatography for the separation of the REEs was introduced by Eugster et al. (1970) and Dosso \& Murthy (1980), where the fractions of Sm and $\mathrm{Nd}$ are separated in a secondary column packed with a cationic resin of the ion ammonium type. The elements are separated as organometalic complexes formed with the 2-hidroxi-isobutiric acid ( $\alpha$-HIBA). The method presents good resolution, and the fractions of Sm and $\mathrm{Nd}$ are practically free from other interfering elements. It is, however, a tedious and time-consuming method and the results do not present significant differences from those obtained by the previous method. Less 
commonly used is the method that uses the anion exchange resin and acetic acid - nitric acid and methanol as eluent (Hooker et al. 1975, O'Nions et al. 1977). It is more efficient than the one that uses HDEHP, however it is necessary to work with the ${ }^{142} \mathrm{Nd}$ isotope which has ${ }^{142} \mathrm{Ce}$, as an important isobaric interferent. A fast technique is the chromatography of high resolution Liquid Chromatography of High Resolution - HPLC (High Performance Liquid Chromatography), and Ionic Chromatography of High Resolution - HPIC (High Performance Ion Chromatography) which present high resolution and speed (Cassidy \& Chauvel 1989).

\section{Separation Technique Used in Brasília}

In Brasília we decided for the method using the HDEHP, with the use of the commercial LN-spec resin. This also consists of teflon powder impregnated with HDEHP, industrially prepared with a very small grain size ( 270 to $150 \mathrm{mesh}$ ). It presented very good efficiency for the separation of $\mathrm{Ce}$ and this element is almost totally absent in the $\mathrm{Nd}$ fractions (isobaric with ${ }^{142} \mathrm{Ce}$ ). Another form of eliminating the interference of $\mathrm{Ce}$ is to avoid the use of ${ }^{142} \mathrm{Nd}$ isotope for fractionation and isotope dilution calculations.

Significant amounts of $\mathrm{Pr}$ were found in the $\mathrm{Nd}$ fraction, however this element does not represent an interferent when $\mathrm{Nd}$ isotopic measurements are done in the metallic form $\left(\mathrm{Nd}^{+}\right)$ instead of the oxide form, when small interference with Pr oxides, with masses 158 and 159 happen (Richard et al. 1976). In the same way, samples with high Ba concentrations, can also present an ineffective separation of $\mathrm{Ba}$ in the secondary column, which was proven to the case in the experiments in this study. However this does not interfere either in the Nd measurement, because it is ionized before the $\mathrm{Nd}$ analysis start due to its lower ionisation temperature (Thirwall 1982). Most of the Ba can be removed during the process of chromatographic separation, eluting the solution with $\mathrm{HNO}_{3}$ in a cationic resin, before the secondary elution for separation of Sm and Nd (Verma 1991), or still using the methodology presented by Stray \& Dahlgren (1995), which combines classic chromatography of ionic change and HPIC for the separation and quantification of REEs in geological samples, based on the method of Le Roex \& Watkins (1990).

The separation procedure used in the University of Brasília was efficient for the separation of $\mathrm{Sm}$ and $\mathrm{Nd}$ and, although time consuming, the procedure is simple and sufficiently effective. This is based, firstly, in the separation of the REE group, using a cation resin (primary column) followed by the extraction of $\mathrm{Nd}$ and $\mathrm{Sm}$ through a partition separation of phase-reverse (HDEHP), both using $\mathrm{HCl}$ as eluent.

\section{Extraction of Sm and Nd of Rock Samples}

\section{Sample Digestion}

50 to $100 \mathrm{mg}$ of rock sample is mixed with the spike and the mixture is dissolved in teflon bombs covered with a steel jacket, using $1 \mathrm{~mL}$ of distilled conc. $\mathrm{HNO}_{3}$ and $4 \mathrm{~mL}$ of concentrated and 
distilled HF. Dissolution is followed by evaporation using a mounted evaporation system with infrared lamps and teflon capsules. The residue is taken again in $\mathrm{HF}: \mathrm{HNO}_{3}$ (4:1) mixture and back to the oven at ca. $190^{\circ} \mathrm{C}$ for 4 days. After complete dissolution, the sample was dried down and 2 $\mathrm{mL}$ of concentrated $\mathrm{HNO}_{3}$ were added. The solution was dried down again, a new attack with 6 $\mathrm{mL}$ of distilled $6 \mathrm{~N} \mathrm{HCl}$ follows. The solution should be absolutely clear and homogeneous at this stage. Complete evaporation of the solution sample and addition of $2 \mathrm{~mL}$ of distilled $2.5 \mathrm{~N} \mathrm{HCl}$ follows. During the course of the study the evaporation procedure was modified. Samples are now evaporated on hot plates, inside clean air cabinets (class-100 air) placed in fume cupboards. This allows cleaner environment for the evaporation, and also allows the evaporation of a large number of samples at the same time.

As already observed in other studies (Getty et al. 1993, Rehkamper et al. 1996 and Sato 1998), we had successful attacks using Savilex ${ }^{\circledR}$ capsules. Some samples, however, such as garnet-rich rocks and some ultramaphic rocks were not entirely dissolved and needed to be transferred to bombs.

\section{Separation of the REEs (Calibration of the Primary Column)}

A quartz column (i.d. $=8 \mathrm{~mm}$ and height $=15 \mathrm{~cm}$ ) was packed with $\sim 2.2 \mathrm{~g}$ (it evaporates for $60^{\circ} \mathrm{C}$ ) or $12 \mathrm{~cm}$ of cation resin Bio-Rad AG 50W-X8 200-400 mesh in aqueous solution. The sample solution is eluted in the column using $\mathrm{HCl}$ (Fig. 1). The REE group is collected in the fraction between 1 and $15 \mathrm{~mL}$ of $6 \mathrm{~N} \mathrm{HCl}$, after elution with $32 \mathrm{~mL}$ of $2.5 \mathrm{~N} \mathrm{HCl}$. Together, with the REEs, $\mathrm{Y}$ and $\mathrm{Ba}$ are also collected (Richard et al. 1976). The column is regenerated with ca. $15 \mathrm{~mL}$ of $6 \mathrm{~N} \mathrm{HCl}$ and stored in diluted acid solution.

The $2.5 \mathrm{~N} \mathrm{HCl}$ was standardized by titrimetry, with $\mathrm{NaCO}_{3}$ (anhydrous) as base and methyl orange as indicator.

\section{Separation of Sm and Nd (Calibration of the Secondary Column)}

The secondary columns are made of teflon (Savilex $\left.{ }^{\circledR}\right)($ i.d. $=5 \mathrm{~mm}$ and height $=10 \mathrm{~cm}$ ) and packed with LN-Spec resin (liquid resin HDEHP-270-150 mesh powdered teflon coated with di-ethylexil phosphoric acid). Height of resin bed is $6.5 \mathrm{~cm}$. The REE fractions were totally evaporated and re-dissolved in $200 \mu \mathrm{L}$ of $0.18 \mathrm{~N} \mathrm{HCl}$. This solution was loaded into the $\mathrm{LN}-\mathrm{Spec}$ column. The $\mathrm{Nd}$ fraction was collected in $4 \mathrm{~mL}$ of $0.3 \mathrm{~N} \mathrm{HCl}$ after the initial $10 \mathrm{~mL}$ of $0.18 \mathrm{~N} \mathrm{HCl}$ (Fig. 2). After the extraction of $\mathrm{Nd}, 2 \mathrm{~mL}$ of $0.3 \mathrm{~N} \mathrm{HCl}$ were discarded and the $\mathrm{Sm}$ fraction was collected in $4 \mathrm{~mL}$ of $0.4 \mathrm{~N} \mathrm{HCl}$, with a flow speed of $\sim 1 \mathrm{~mL} / 30 \mathrm{~min}$. The regeneration of the resin was achieved with $6 \mathrm{~mL}$ of $6 \mathrm{~N} \mathrm{HCl}$. The column was conditioned again with the purified $3 \mathrm{~mL}$ of $\mathrm{H}_{2} \mathrm{O}$ (Nanopure) followed by $2 \times 3 \mathrm{~mL}$ of $0.18 \mathrm{~N} \mathrm{HCl}$.

\section{Chromatographic Columns for Minerals}

Smaller columns, where set up for extracting Sm and Nd from low-REE materials. 


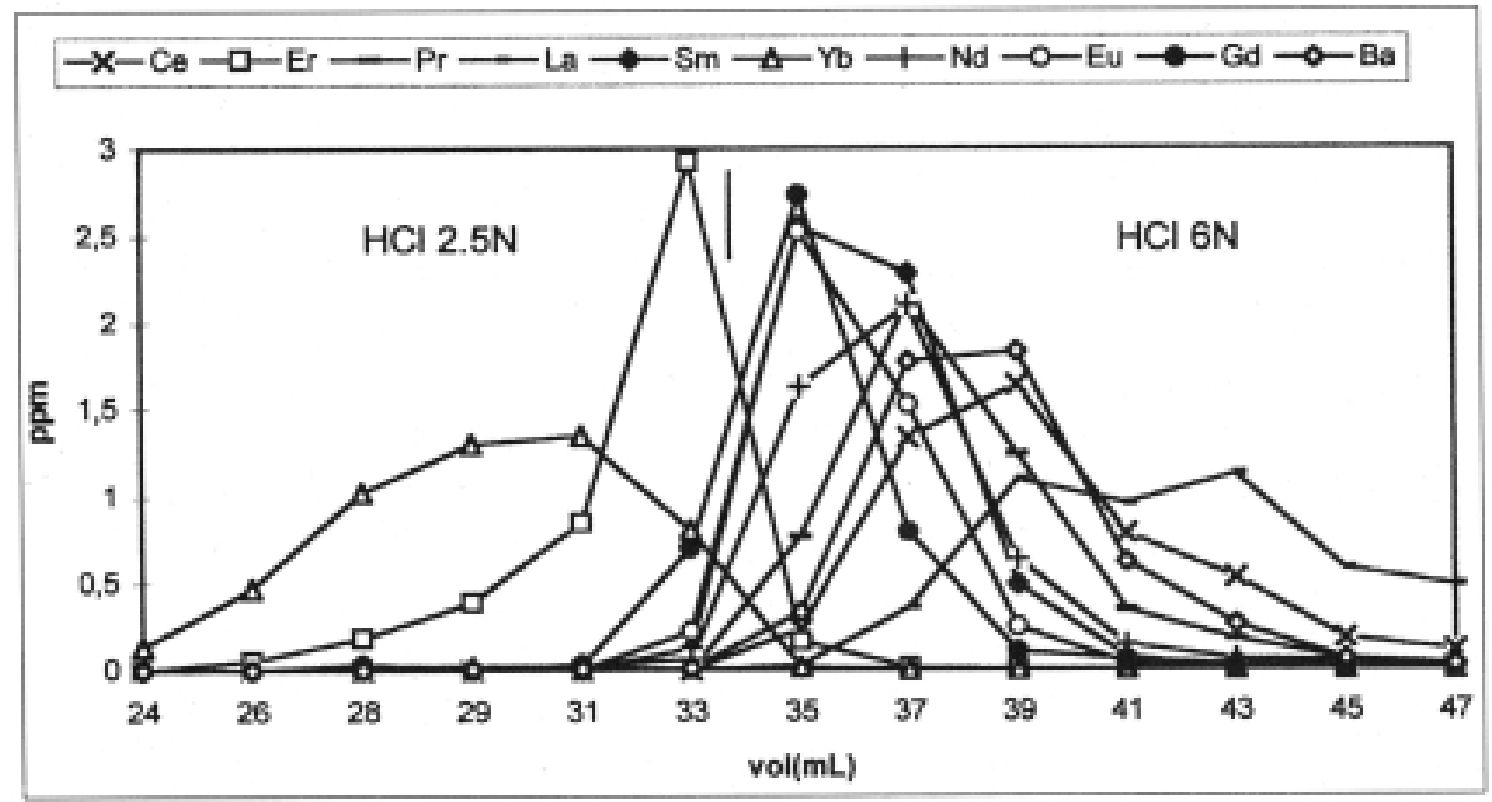

Fig. 1 - Separation of the REE group from the main elements of the rock.

As shown in Fig. 3a, the calibration showed the efficiency of the small columns for the separation of the REEs, using the Bio-Rad AG50W-X8 resin. The resolution of the secondary column (Fig. 3b) was also very good for separation of Sm-Nd, Ce-Nd, and Sm-Gd.

\section{REE Separation (Primary Column)}

The column was packed with cation resin to a height of $7 \mathrm{~cm}$ (column of i.d. $=5 \mathrm{~mm}$ and height of $10 \mathrm{~cm}$ ). The flow speed was set at ca. $1 \mathrm{~mL} / 10 \mathrm{~min} .250 \mu \mathrm{L}$ of sample were added and washed with three times $250 \mu \mathrm{L}$ of $2.5 \mathrm{~N} \mathrm{HCl} .7 \mathrm{~mL}$ of $2.5 \mathrm{~N} \mathrm{HCl}$ were discarded and the REE fraction comes out in $5 \mathrm{~mL}$ of $6 \mathrm{~N} \mathrm{HCl}$. The column was regenerated with $15 \mathrm{~mL}$ of $6 \mathrm{~N} \mathrm{HCl}$. Satisfactory results have also been obtained working with a larger aliquot of sample (500 $\mu \mathrm{L})$.

\section{Sm-Nd Separation}

The column was packed with the LN-spec resin to a height of $7 \mathrm{~cm}(\sim 100 \mathrm{mg})$ and $0.5 \mathrm{~cm}$ of anionic resin Bio-Rad 200-400 mesh was added on top. The flow speed was set at $1 \mathrm{~mL} / 50 \mathrm{~min}$. $100 \mu \mathrm{L}$ of sample in $0.18 \mathrm{~N} \mathrm{HCl}$ was added and washed three times with the same amount of $0.18 \mathrm{~N}$ $\mathrm{HCl}$. The elution was carried out (Fig. 3b) with $0.18 \mathrm{~N} \mathrm{HCl}$. The first $6 \mathrm{~mL}$ were discarded and $\mathrm{Nd}$ was extracted in $3 \mathrm{~mL}$ of $0.3 \mathrm{~N} \mathrm{HCl}$. Elution of $2 \mathrm{~mL}$ of $0.3 \mathrm{~N} \mathrm{HCl}$, followed and $\mathrm{Sm}$ is extracted in $3 \mathrm{~mL}$ of $0.4 \mathrm{~N} \mathrm{HCl}$. The column is regenerated with $5 \mathrm{~mL}$ of $6 \mathrm{~N} \mathrm{HCl}$. 


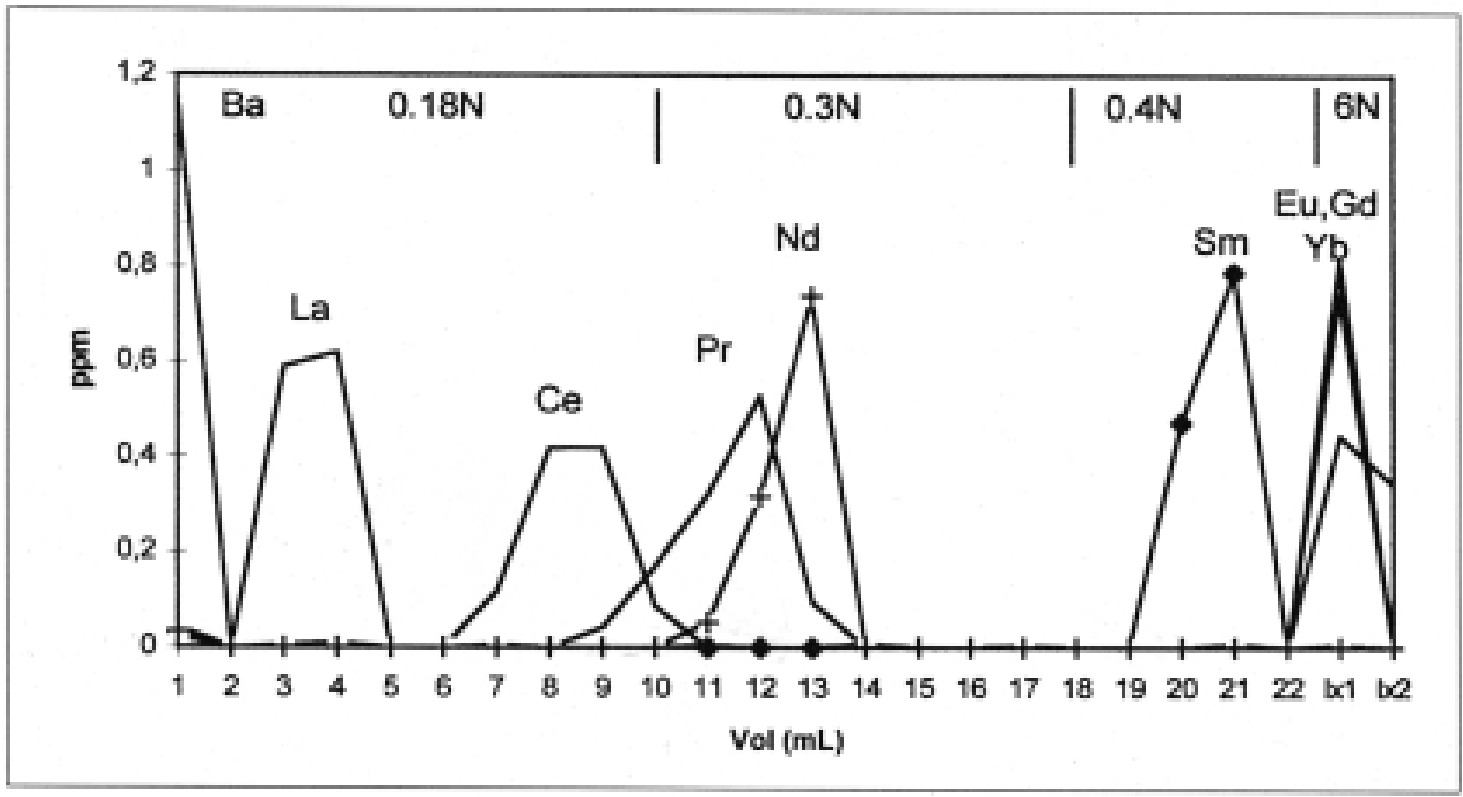

Fig. 2 - Sm and Nd separation. The calibration was made with $\mathrm{LN}$-spec resin (HDEHP resin impregnated in teflon powder of 150-270 mesh). $\mathrm{HCl}$ was used as eluent in the calibration.

\section{Preliminary StUdies}

\section{Partition Coefficient and Separation Factor}

The selectivity (Table I) of the liquid HDEHP, using a fine graned (270-150 mesh) powdered teflon as support, showed better efficiency than using a coarse powder (60-40 mesh), due to the increase in the ion exchange capacity of the resin. In Fig. 4a, the ion exchange reverse behaviour of HDEHP resin is observed, where the light REEs are first eluted. For the separation of Ba-La-Ce-Pr-Nd, the best concentration of $\mathrm{HCl}$ to be used proved to be $0.18 \mathrm{~N}$. This has been already observed empirically during the calibration and later on with the determination of the partition coefficient (Fig. 4b). For the separation of Sm-Eu-Gd the best concentration of $\mathrm{HCl}$ proved to be between 0.35 and $0.4 \mathrm{~N}$ (Fig. 4c and d). In this concentration, a large separation factor (ratio between the coefficients of distribution of these elements) is observed. The separation of Nd-Sm happens in concentrations $\leq 0.3 \mathrm{~N}$ (Fig. $4 \mathrm{e}$ and $\mathrm{f}$ ). The use of stronger acids will result in the elution of some of the $\mathrm{Sm}$ into the Nd fraction.

\section{RESULTS AND DISCUSSION}

\section{Analytical Procedure (Mass Spectrometry)}

The fraction collected in the secondary column is evaporated with 2 drops of $0.025 \mathrm{~N} \mathrm{H}_{3} \mathrm{PO}_{4}$. The residue is dissolved in $1 \mu \mathrm{L}$ of $5 \%$ distilled $\mathrm{HNO}_{3}$ loaded onto a Re filament of double 


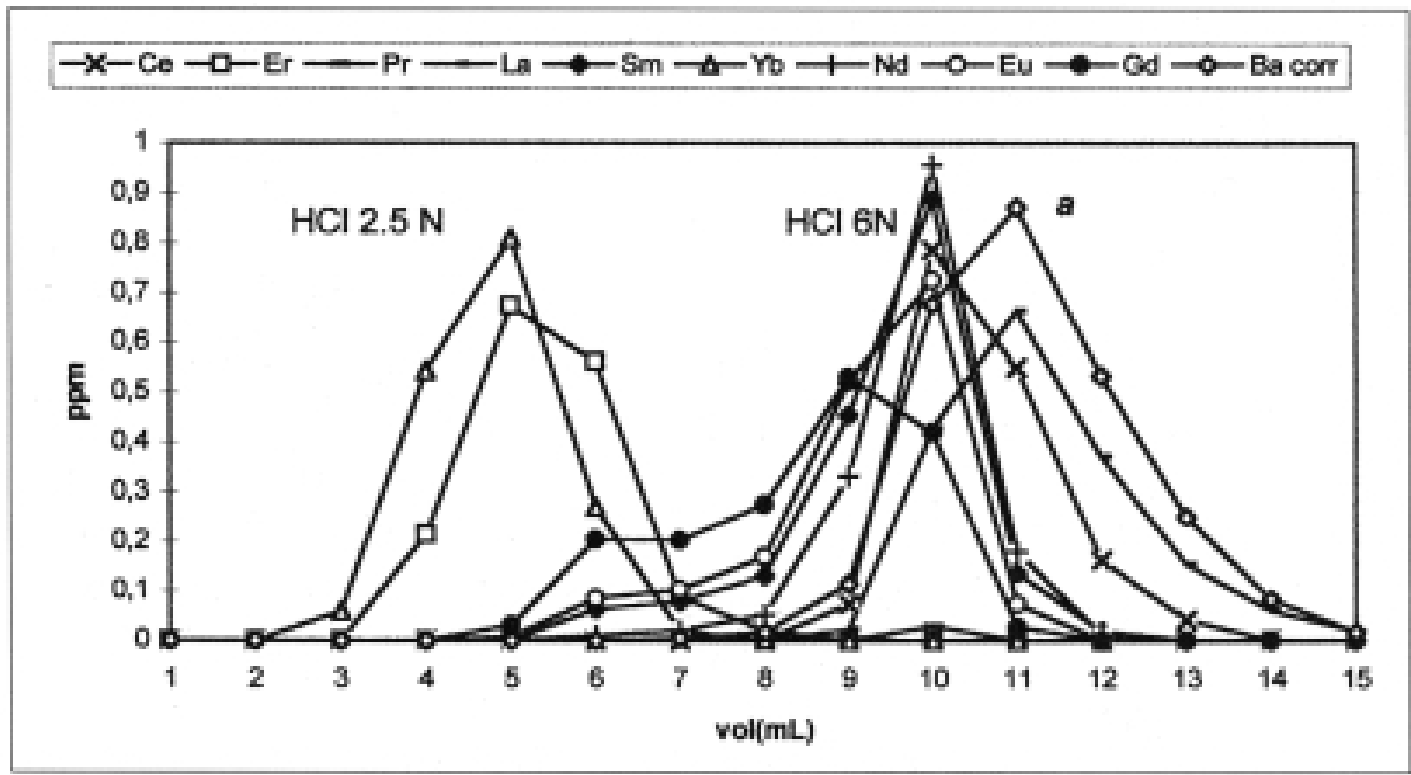

Fig. 3a-Columns calibration for minerals analysis: REEs elution, where was necessary the concentration correction from blank value obtained in ICP/AES for Ba element.

TABLE I

Chromatographic Columns Resolution

\begin{tabular}{|c|c|c|c|c|c|}
\hline \multicolumn{6}{|c|}{ Results } \\
\hline Separation & \multicolumn{3}{|c|}{ Separation Columns for Rock Analysis } & \multicolumn{2}{|c|}{$\begin{array}{c}\text { Separation Columns for Minerals } \\
\text { Analysis }\end{array}$} \\
\hline lanthanide & $\begin{array}{l}\text { Col. HDEHP 40-60 } \\
\text { mesh }\end{array}$ & $\begin{array}{l}\text { Col. HDEHP } \\
\text { 150-270 mesh }\end{array}$ & $\begin{array}{l}\text { Col. BioRad 8X } \\
\text { 200-400 mesh }\end{array}$ & $\begin{array}{l}\text { Col. HDEHP } \\
\text { 150-270 mesh }\end{array}$ & $\begin{array}{c}\text { Col. BioRad 8X } \\
\text { 200-400 mesh }\end{array}$ \\
\hline $\mathrm{La}-\mathrm{Ce}$ & - & 1.42 & - & 1.2 & - \\
\hline $\mathrm{Ce}-\mathrm{Nd}$ & - & 1.0 & - & 1.3 & - \\
\hline Pr-Nd & - & & - & 0.7 & - \\
\hline $\mathrm{Nd}-\mathrm{Sm}$ & 1.5 & 2.4 & - & 4.0 & - \\
\hline $\mathrm{Sm}-\mathrm{Eu}$ & - & & - & 2.0 & - \\
\hline $\mathrm{Ca}-\mathrm{Sr}$ & - & - & 1.1 & - & 0.6 \\
\hline $\mathrm{Rb}-\mathrm{Sr}$ & - & - & 2.2 & - & \\
\hline
\end{tabular}

filament assembly. The mass spectrometer used was a Finnigan MAT 262 with 7 collectors and the analyses have been accomplished in static mode. The ${ }^{143} \mathrm{Nd} /{ }^{144} \mathrm{Nd}$ ratio was normalised using ${ }^{146} \mathrm{Nd} /{ }^{144} \mathrm{Nd}=0.7219$ and the decay constant used was the value revised by Lugmair \& Marti (1978) of $6.54 \times 10^{-12} / \mathrm{y}$. The external precision (Table II) for ${ }^{143} \mathrm{Nd} /{ }^{144} \mathrm{Nd}$ ratios obtained for the 


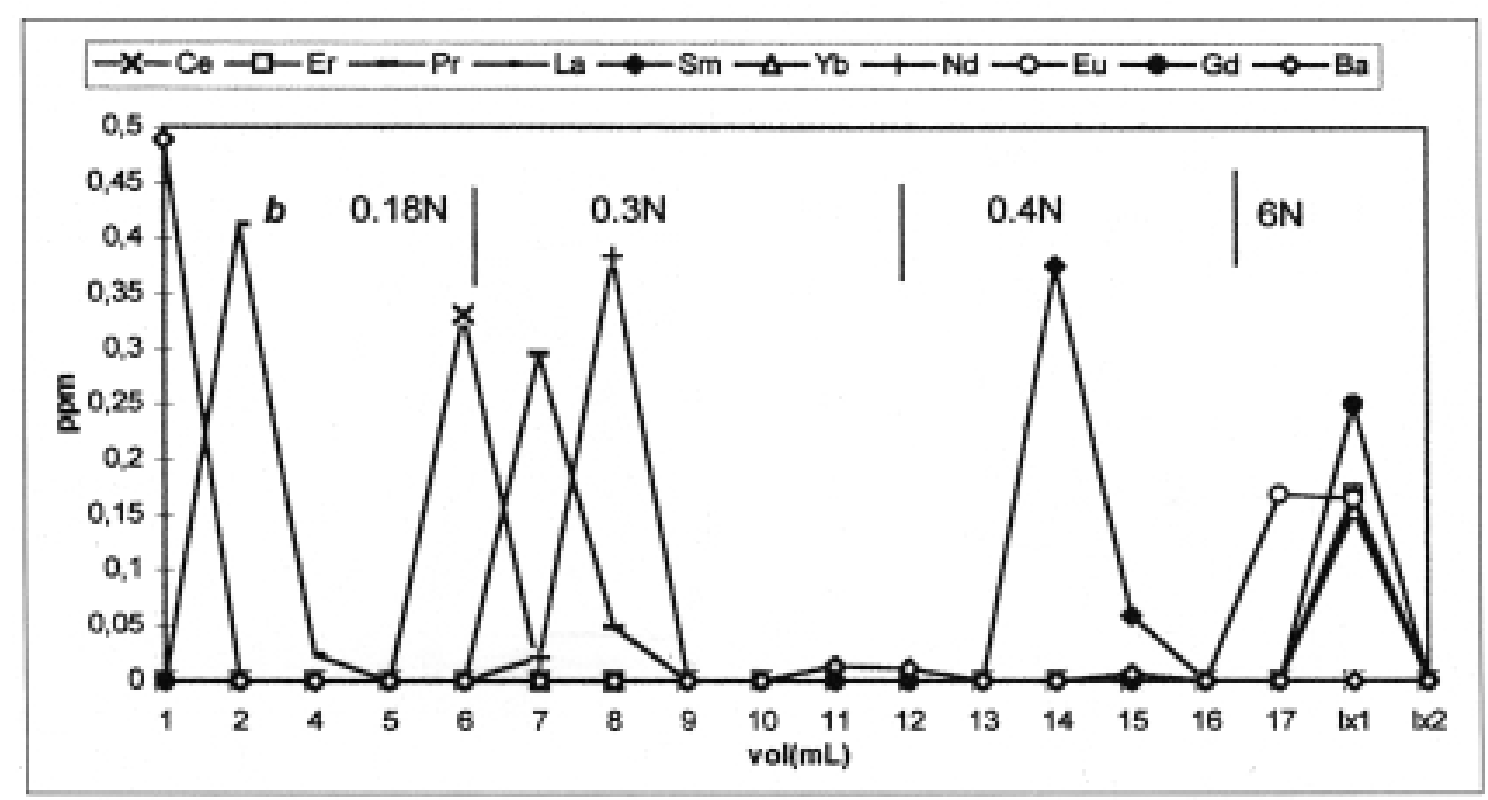

Fig. $3 \mathrm{~b}$ - Columns calibration for minerals analysis: Sm and Nd separation.

different rock standards used varied between $0.0006-0.0016 \%$ and the analytical uncertainty for ${ }^{147} \mathrm{Sm} /{ }^{144} \mathrm{Nd}$ ratio was smaller than $0.19 \%$.

TABLE II

Statistical treatment for the obtained data

\begin{tabular}{l|ccc|c}
\hline Standard & \multicolumn{3}{|c}{$\mathrm{SD} \%$} & \multicolumn{2}{c}{${ }^{* 147} \mathrm{Sm} /{ }^{144} \mathrm{Nd}$} \\
& ${ }^{143} \mathrm{Nd} /{ }^{144} \mathrm{Nd}$ & $\mathrm{Nd}$ & $\mathrm{Sm}$ & $(\%$ error $)$ \\
\hline BCR-1 & 0.0007 & $0.3-0.4$ & 0.7 & 0.11 \\
BHVO-1 & 0.0016 & 0.2 & 0.03 & 0.009 \\
JB3 & 0.0006 & 0.06 & 0.8 & 0.19 \\
\hline
\end{tabular}

$\mathrm{SD} \%=$ external precision.

*analytical error for the ratio ${ }^{147} \mathrm{Sm} /{ }^{144} \mathrm{Nd}$.

\section{AnAlytic Control}

International rock standards with very well-known $\mathrm{Sm}$ and $\mathrm{Nd}$ concentrations and $\mathrm{Nd}$ isotopic composition were analyzed. The analyses of these standards were necessary to test the reproducibility of the data and mainly to evaluate the reliability of the methodology in rocks of unknown composition. The standards used (Table III) were: BCR-1 (Ballast-USGS), JB3 (Basalt-GSJ), BHVO-1 (Basalt Hawaiian-USGS), JG2 (Granite-GSJ) and La Jolla. 

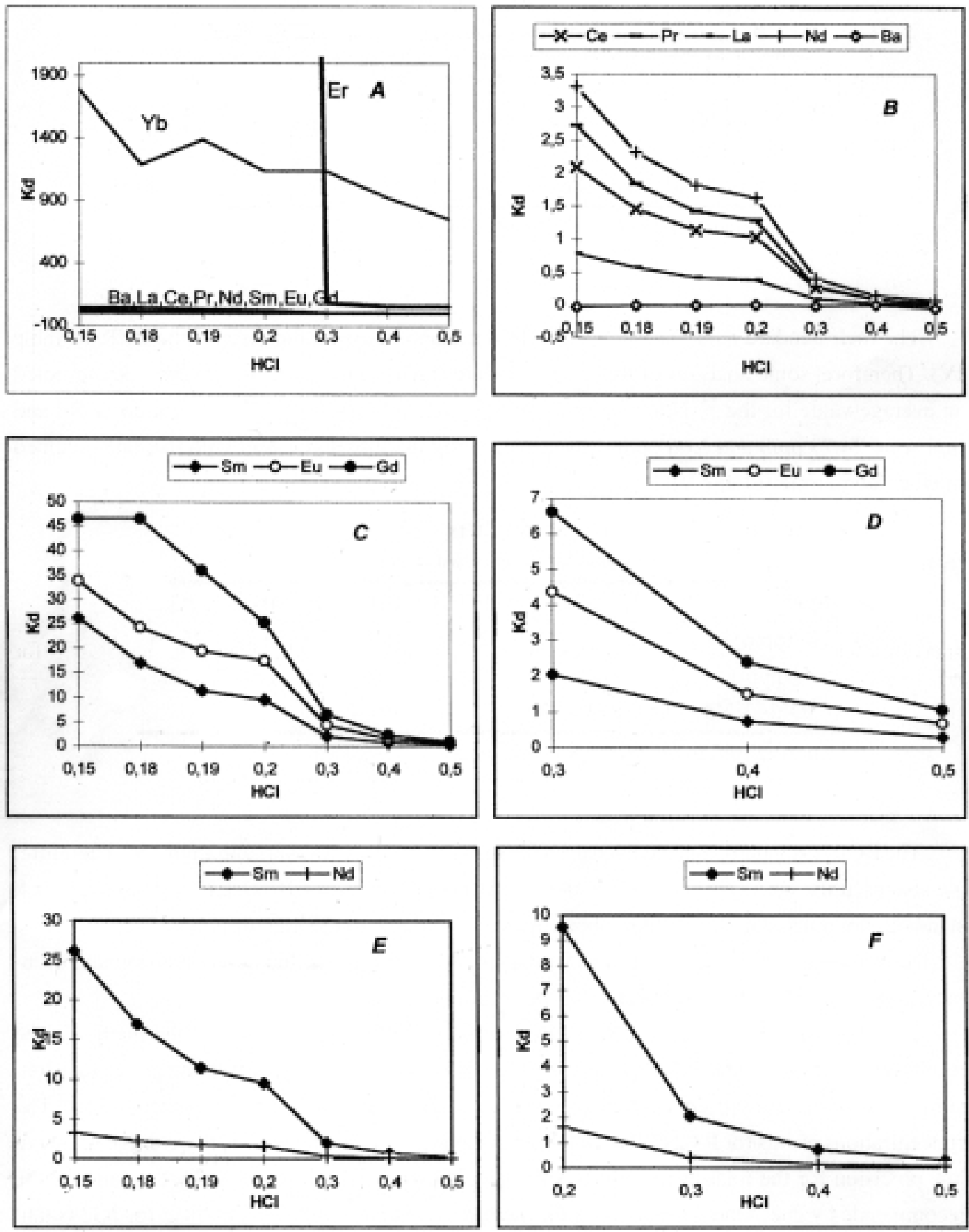

Fig. 4 - Determination of lanthanides partition coefficients. 
TABLE III

Recommended values for the used standards (Govindaraju 1994)

\begin{tabular}{lccccc}
\hline Standards & La Jolla & BCR-1 & BHVO-1 & JB3 & JG2 \\
\hline $\mathrm{Nd}(\mathrm{ppm})$ & - & 28.8 & 25.2 & 15.4 & 25.8 \\
$\mathrm{Sm}(\mathrm{ppm})$ & - & 6.59 & 6.2 & 4.27 & 7.72 \\
${ }^{143} \mathrm{Nd} /{ }^{144} \mathrm{Nd}$ & $0.511860^{*}$ & - & - & - & - \\
\hline
\end{tabular}

${ }^{*}$ normalised to ${ }^{146} \mathrm{Nd} /{ }^{144} \mathrm{Nd}=0.7219$.

The rock standard most frequently used for interlaboratorial comparison is the BCR-1 (Table IV). Therefore, some analyses of this standard were carried out during this study. They revealed an average value for the ${ }^{143} \mathrm{Nd} /{ }^{144} \mathrm{Nd}$ ratio of $0.512632 \pm 2(1 \sigma, \mathrm{n}=5)$. Concentration of $\mathrm{Nd}$ and $\mathrm{Sm}$, were $28.73 \mathrm{ppm}$ and $6.66 \mathrm{ppm}$ respectively being in close agreement with the data obtained in other laboratories (Table V).

TABLE IV

Values for the analysed standards

\begin{tabular}{lccccc}
\hline Standards & La Jolla & BCR-1 & BHVO-1 & JB3 & JG2 \\
\hline $\mathrm{Nd}(\mathrm{ppm})$ & - & 28.73 & 24.83 & 15.74 & 25.16 \\
$\mathrm{Sm}(\mathrm{ppm})$ & - & 6.66 & 6.2 & 4.28 & 8.22 \\
${ }^{143} \mathrm{Nd} /{ }^{144} \mathrm{Nd}$ & $0.511835 \pm 14^{*}$ & - & - & - & - \\
\hline *normalised to & ${ }^{146} \mathrm{Nd} /{ }^{144} \mathrm{Nd}=0.7219$ & & &
\end{tabular}

The BCR-1 standard, that has been used for so many years, is not available anymore. Therefore, we also used the BHVO-1 standard (Table IV). However, because BHVO-1 is only a recent rock standard, not much data from other laboratories are available in the literature.

Nevertheless, results for BCR-1, as well as for BHVO-1, presented good precision and accuracy, with the values being comparable to the recommended values.

The results for JB-3 and JG-2 were used in the preliminary evaluation of the method. The results obtained for standard JB-3 (a basalt) (Table IV) were satisfactory, presenting good precision, although the $\mathrm{Sm}$ and $\mathrm{Nd}$ concentrations were consistently $2 \%$ below the expected value. The concentrations results for JG-2 (Table IV) showed much greater scatter around the average, showing low precision for the final mean value. This value, however, is still statistically the same as the recommended value. One interpretation for the low precision of the data obtained for JG2 is that the standard is not as homogeneous (regarding the REE) as the other three rocks standards. This is only to be expect, because JG2 is a granite standard.

The data for the La Jolla standard in this study tended to be somewhat lower (Table IV) than the recommended value of 0.511860 (USGS). The average value of $0.511835 \pm 14(1 \sigma)$ obtained 


\section{TABLE V}

Interlaboratorial Comparison

\begin{tabular}{|c|c|c|c|c|}
\hline \multirow{2}{*}{$\begin{array}{l}\text { Laboratories/ } \\
\text { references }\end{array}$} & \multirow[t]{2}{*}{ Equipment } & \multirow{2}{*}{$\begin{array}{c}\text { BCR1 } \\
{ }^{143} \mathrm{Nd} /{ }^{144} \mathrm{Nd}^{*}\end{array}$} & \multicolumn{2}{|c|}{ BCR1 } \\
\hline & & & $\mathrm{Nd}(\mathrm{ppm})$ & $\operatorname{Sm}(\mathrm{ppm})$ \\
\hline This study (UnB) & MAT 262 & $0.512647(8)$ & 28.73(13) & $6.66(2)$ \\
\hline IG-USP (Kawashita et al. 1991 & VG ISOMASS 354 & $0.512662(29)$ & 28.52 & 6.53 \\
\hline PML-Japão (Makobo \& Nakamura 1995) & & $0.512630(3)$ & & \\
\hline RSES-Austrália (Sun et al. 1995) & MAT 261 & $0.512653(5)$ & & \\
\hline (Gladney et al. 1983) & & & 28.7 & 6.58 \\
\hline Kobe-Japão (Nakamura 1974) & & & 28.8 & 6.72 \\
\hline Oxford (Hooker et al. 1975) & & & 29.30 & 6.67 \\
\hline (Thirlwall 1991) & & 0.512643 & & \\
\hline MAINZ (Ito et al. 1987) & & 0.512647 & & \\
\hline (Wasserburg et al. 1981) & & $0.512647(20)$ & & \\
\hline
\end{tabular}

*normalised to ${ }^{146} \mathrm{Nd} /{ }^{144} \mathrm{Nd}=0.7219$.

is, however, statistically the same as the recommended if $2 \sigma$ uncertainties are considered.

The average value obtained for the La Jolla standard is comparable with the values obtained in other laboratories (Table V). Our mean value of $0.511835 \pm 0.000014$ is statistically the same as the expected value of 0.511850 (average of all laboratories).

$\mathrm{Nd}$ procedure blanks (Table VI) decreased from $385 \mathrm{pg}$ in the beginning of this study to ca. $74 \mathrm{pg}$ towards the end. Nowadays these blanks are commonly around $30 \mathrm{pg}$. Blanks tend to be smaller when dissolution is carried out in Savillex ${ }^{\circledR}$ capsules.

\section{TABLE VI}

\section{Experimental blank data for Nd in the Geochronol- ogy Laboratory of the Brasília}

\begin{tabular}{lc}
\hline Analyse & $\mathrm{Nd}(\mathrm{pg})$ \\
\hline Total Blank 1 (Bomb) & 385 \\
Total Blank 2 (Bomb) & 144 \\
Total Blank 3 (Bomb) & 74 \\
Total Blank 1 (Savilex $\left.{ }^{\circledR}\right)$ & 50 \\
Total Blank of Separation Columns & $12-20$ \\
\hline
\end{tabular}

The Nd total blanks observed in Geochronology laboratory of the UnB is within the range of values obtained in other laboratories of the world (Table VII and Fig. 5). As shown in Table VI 
the LN-Spec resin contribute little to the total blank indicating that the largest contribution for the blank is the memory effect in the dissolution vessels, as well as the reagents.

TABLE VII

Summary of obtained data for total blank in other geochronology laboratories

\begin{tabular}{lcl}
\hline Laboratory/Reference & Blank Nd(pg) & Experimental Conditions \\
\hline HARVARD/(Getty et al. 1993) & 20 & savilex/acid dissolution \\
SUNNY/(Hemning et al. 1995) & 200 & fusion with $\mathrm{LiBO}_{2}$ \\
RSES/(Zhao \& McCulloch 1995) & $25-100$ & Bomb/acid dissolution \\
RSES/(Sun et al. 1995) & $<50$ & Bomb/acid dissolution \\
RENNES/(Chavagnac \& Jahn 1996) & 180 & Savilex and Bomb \\
& & acid dissolution \\
(Mukasa et al. 1994) & 40 & teflon vial (PFA) \\
TUCSON/(Patchett \& Ruiz 1987) & 80 & Bomb/acid dissolution \\
PML/(Maboko \& Nakamura 1995) & 10 & Bomb/acid dissolution \\
RENNES/(Tourpin et al. 1991) & 500 & Bomb/acid dissolution \\
DENVER/(Li 1994) & $50-100$ & Bomb/acid dissolution \\
UCLA/(DePaolo 1981) & 1000 (without purification of HCl) & \\
WASHINGTON/(Sorensen \& Wilson 1995) & 51 & Bomb/acid dissolution \\
\hline
\end{tabular}

ISOBARIC INTERFERENCE FOR Sm AND Nd

\section{Samarium}

${ }^{136} \mathrm{CeO}^{+},{ }^{136} \mathrm{BaO}^{+}$(Table VIII) are isobaric interferents with ${ }^{152} \mathrm{Sm}^{+}$. These interferences can be suppressed by the average discharge due to the low ionization potential of these species, while the emission of the ${ }^{152} \mathrm{Gd}^{+}$is inhibited by its high ionisation potential. In this study it was observed that the signal of $\mathrm{BaO}^{+}$is reduced to negligible proportions during the analysis of $\mathrm{Sm}$ and its main contribution, as ${ }^{138} \mathrm{BaO}^{+}$, will only interfere with masses 154 and 155 of $\mathrm{Sm}$, not representing therefore any important interference. Gd was found in inexpressive amounts, as shown in Fig. 6. The amount of Gd is very small and ${ }^{160} \mathrm{Gd}^{+}$does not appear in the mass scan. To avoid any possible interference of $\mathrm{Gd}$ with ${ }^{152} \mathrm{Sm}^{+}$, used for the concentration calculations, we carried out an evaluation of the amount of Sm collected in the chromatographic column (Figs. 6 and 7). Maximum contribution of the mass 155 and detection of the mass 160 is observed when Sm is collected in 4 $\mathrm{mL}$ of $0.5 \mathrm{~N} \mathrm{HCl}$, indicating presence of $\mathrm{Gd}$ and/or the presence of oxide species as the ${ }^{144} \mathrm{NdO}^{+}$or even ${ }^{144} \mathrm{SmO}^{+}$(Fig. 7). In the $3 \mathrm{~mL} \mathrm{Sm}$ fraction an insignificant amount of the mass 155 is present, which is probably due only to the contribution of the La oxide $\left({ }^{139} \mathrm{La}^{+}\right.$present in the scan). It is 


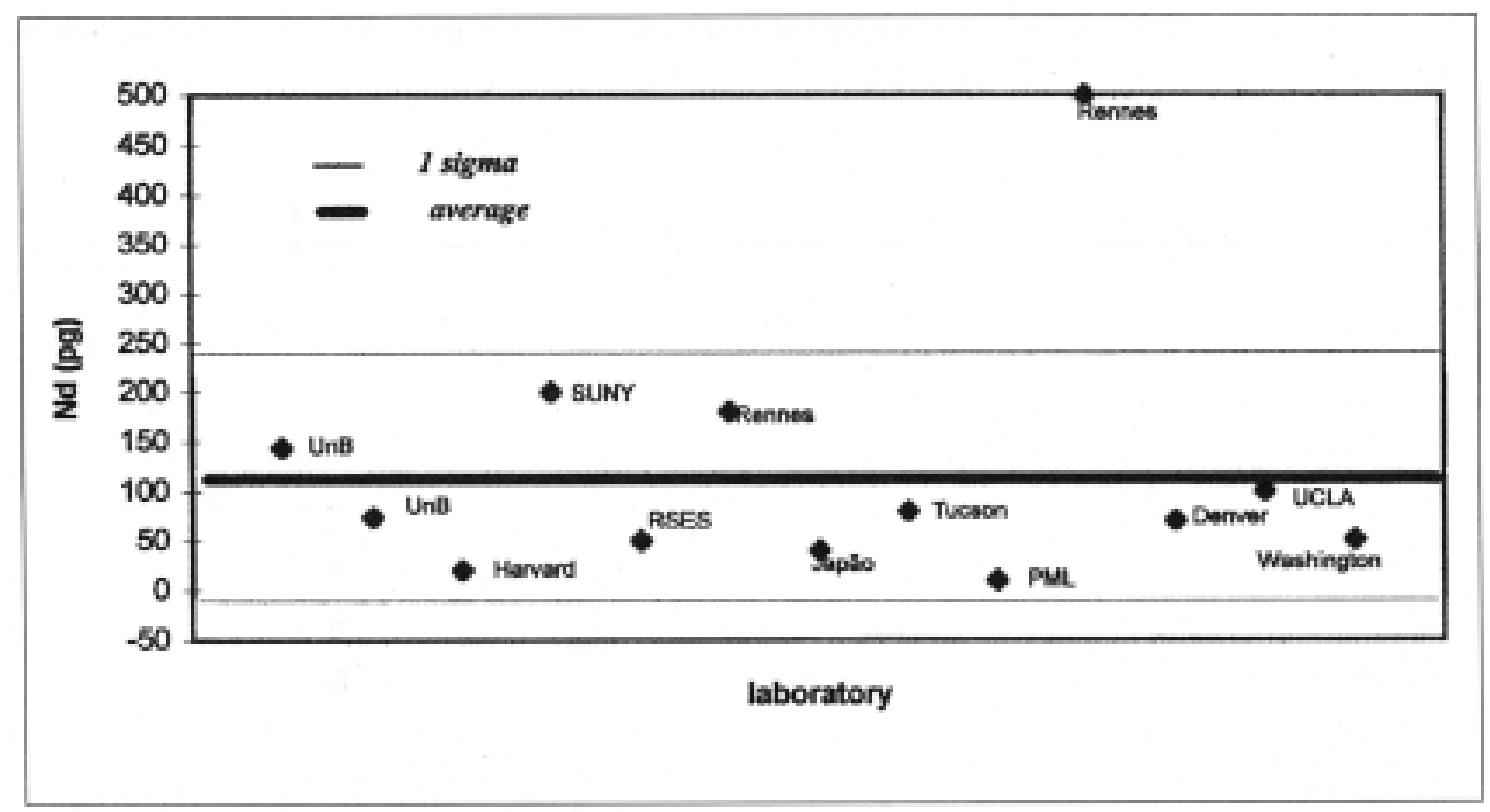

Fig. 5 - Interlaboratorial comparison of the experimental blanks.

observed that, even collecting the Sm fraction in of $4 \mathrm{~mL}$ of eluent, the contribution of the isotope 160 of $\mathrm{Gd}$ is insignificant, being smaller than $5 \mathrm{mV}$, what means a contribution smaller than 0.05 $\mathrm{mV}$ of ${ }^{152} \mathrm{Gd}^{+}$, being therefore, negligible.

TABLE VIII

Mass interferences in Sm isotopic determinations

\begin{tabular}{cccc}
\hline $\mathrm{N}^{\circ}$ of Mass & 147 & 149 & 152 \\
\hline & ${ }^{130} \mathrm{Ba}^{17} \mathrm{O}$ & ${ }^{132} \mathrm{Ba}^{17} \mathrm{O}$ & ${ }^{152} \mathrm{Gd}^{+}$ \\
& & ${ }^{136} \mathrm{Ba}^{16} \mathrm{O}$ \\
& & ${ }^{136} \mathrm{Ce}^{16} \mathrm{O}$ \\
& & & ${ }^{135} \mathrm{Ba}^{17} \mathrm{O}$ \\
\hline
\end{tabular}

\section{Neodymium}

The interference (Table IX) of $\mathrm{BaO}^{+}$is trivial. Most of $\mathrm{Ba}$ is vaporized before the $\mathrm{Nd}$ analysis. Additionally, the natural abundance of the interfering masses $\left({ }^{130} \mathrm{Ba}^{+}\right.$and $\left.{ }^{134} \mathrm{Ba}^{+}\right)$are low $(0.11 \%$ and $2.42 \%$ respectively). Ce interferes (Table IX) with ${ }^{142} \mathrm{Nd}$, however, due to the difficulty in separating $\mathrm{Ce}$ of $\mathrm{Nd}$ totally, it was preferred to use mass 146 as the reference isotope for the fractionation and isotopic dilution calculations. Previous studies have reported the presence of $\mathrm{Ce}$ as an important factor causing instability of the ion beam. In this study even when present in great 


\section{Feb 1997 11:22:48 MASS SACAN CHANNEL 5}

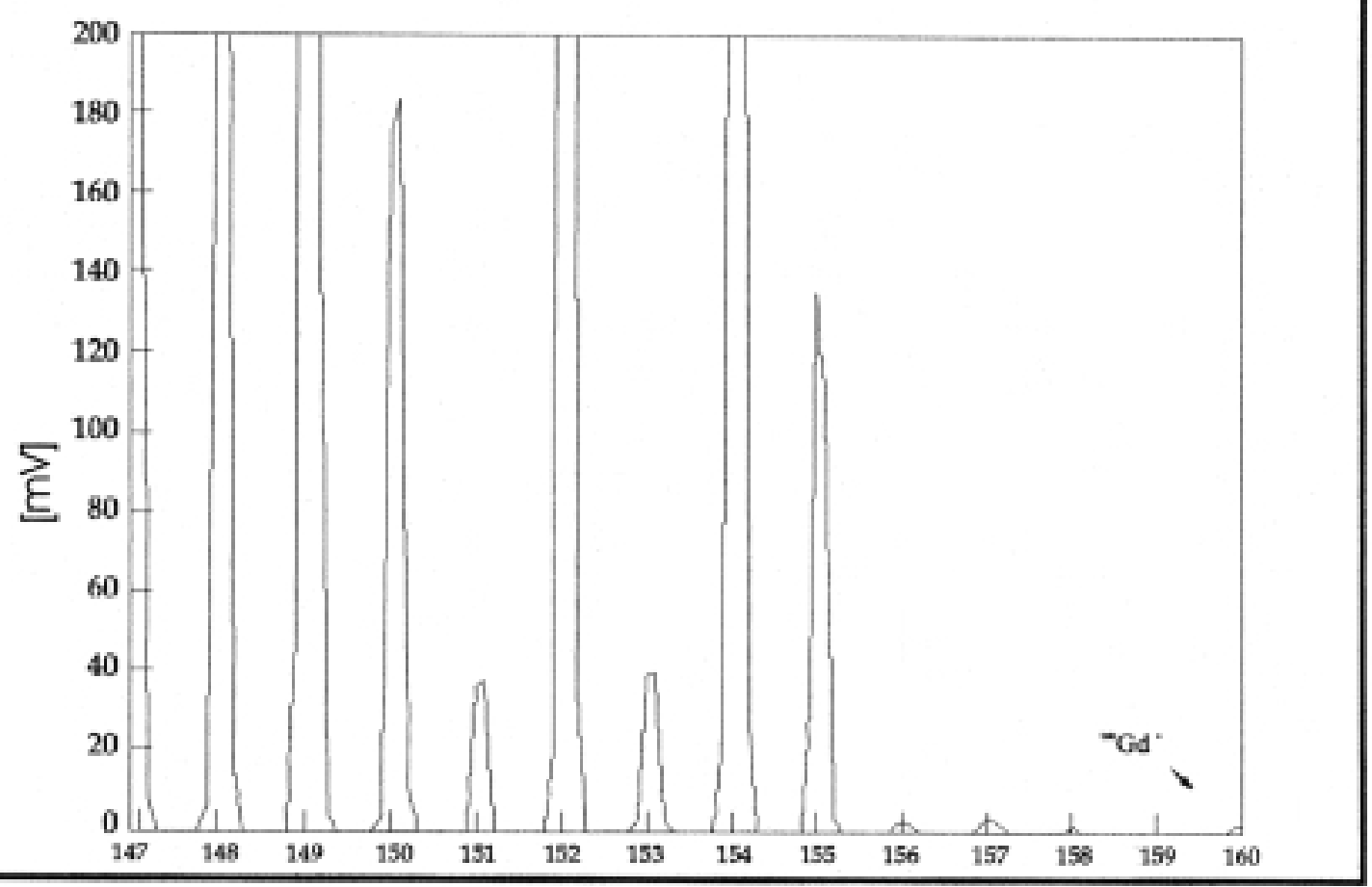

Fig. 6 - Interference of Gd on Sm. Increased scale, with 2.2 volts for ${ }^{149} \mathrm{Sm}$.

amounts, little instability is observed in the beam. This is well displayed in Fig. 8 which shows that presence of $\mathrm{Ce}$ in the $\mathrm{Nd}$ fraction is incapable of generating beam instability.

TABLE IX

Mass interferences in Nd isotopic determinations

\begin{tabular}{cccccc}
\hline $\mathrm{N}^{\circ}$ of Mass & 142 & 143 & 144 & 146 & 150 \\
\hline & ${ }^{142} \mathrm{Ce}^{+}$ & & ${ }^{144} \mathrm{Sm}^{+}$ & ${ }^{130} \mathrm{Ba}^{16} \mathrm{O}$ & ${ }^{150} \mathrm{Sm}^{+}$ \\
& & & & & ${ }^{134} \mathrm{Ba}^{16} \mathrm{O}$ \\
\hline
\end{tabular}

Other isotope present during the analysis of $\mathrm{Nd}$ is ${ }^{141} \mathrm{Pr}^{+}$, but its presence does not represent isobaric interference in the metal form in spite of this. Its interference only happens when $\mathrm{Nd}$ is analyzed in the oxide form.

\section{CONCLUSIONS}

The improved chemical extraction used in this study following the preliminary determination of the partition coefficient of REEs in the HDEHP resin uses the best possible conditions for extraction of 

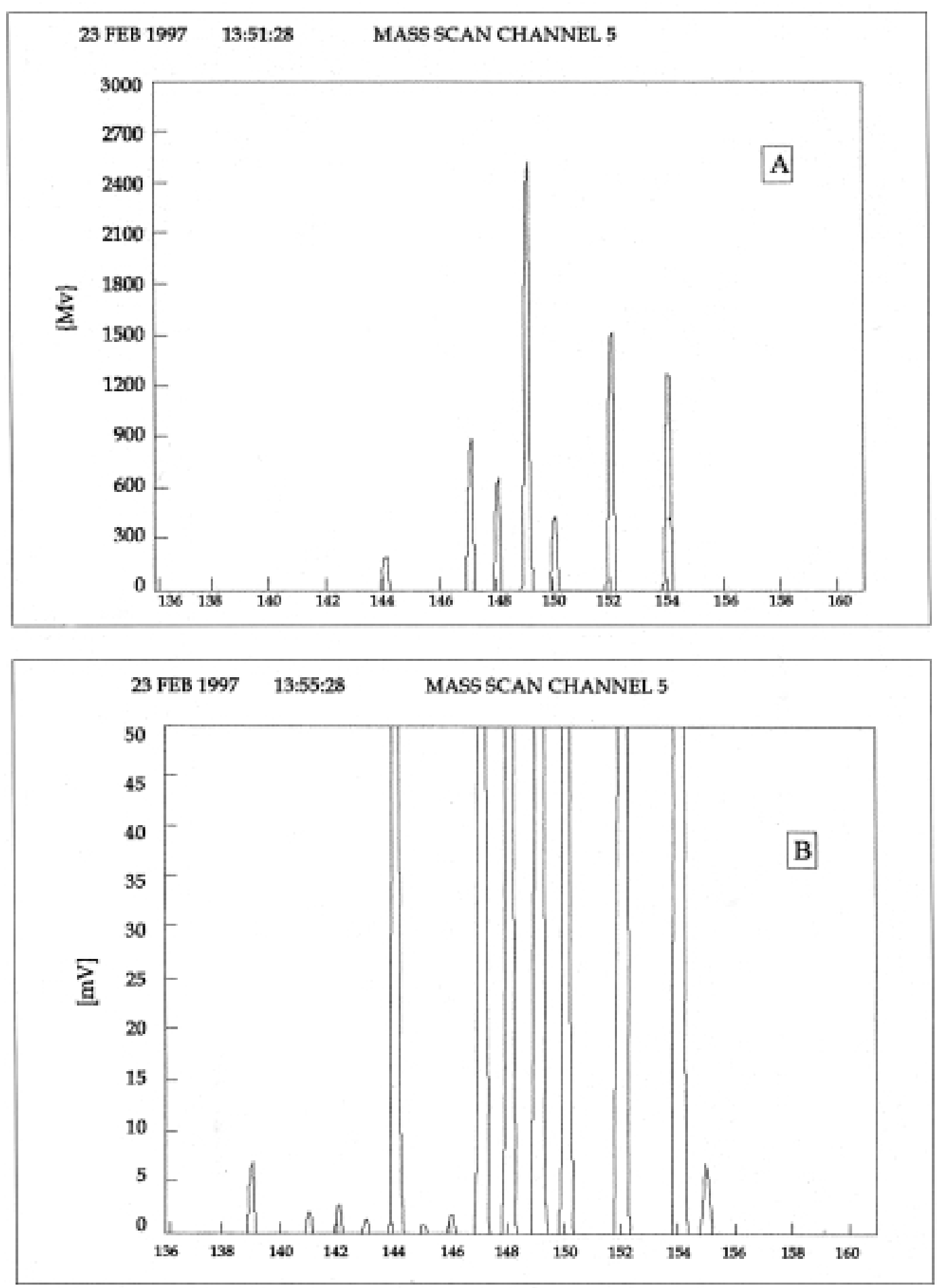

Fig. 7 - Mass interference for Sm. A - increased scale, B - with 2.6 volts for ${ }^{149} \mathrm{Sm}$. 


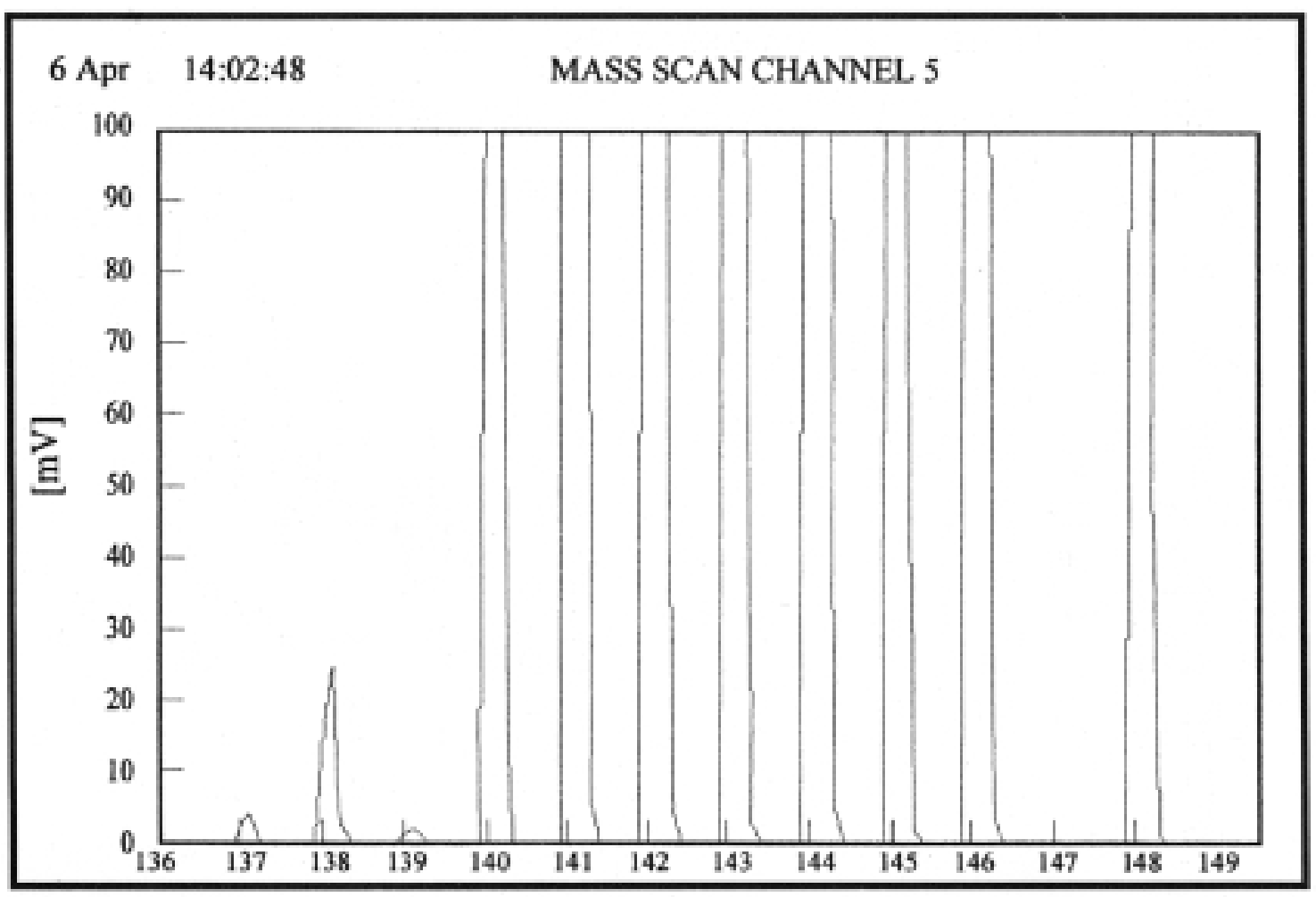

Fig. 8 - Mass interference for Nd. Increased scale, with 2.2 volts for ${ }^{142} \mathrm{Nd}$.

$\mathrm{Sm}$ and $\mathrm{Nd}$. The efficiency of the chemical separation appears in the spectrometric analysis where interferences with other elements are kept to a minimum.

In the mass spectrometry the presence of $\mathrm{Ce}$ and mainly $\mathrm{Pr}$ in the $\mathrm{Nd}$ fraction was observed. There is absolutely no isobaric interference between $\mathrm{Sm}$ and $\mathrm{Nd}$ using this procedure. In the $\mathrm{Sm}$ fraction there are detectable amounts of $\mathrm{Eu}$, but this does not represent a problem, because its isotope do not interfere with the determination of the $\mathrm{Sm}$ isotopic ratios. The main isobaric interference of Sm, Gd, is not detected. Sm and Nd concentrations obtained for the JB3 and BCR-1 rock standards show good accuracy and precision, and isotopic ratio of ${ }^{143} \mathrm{Nd} /{ }^{144} \mathrm{Nd}$ for BCR-1 and La Jolla are comparable to the values obtained in other laboratories, demonstrating the reliability of the methodology used at the University of Brasília.

\section{ACKNOWLEDGEMENTS}

The authors thank CAPES and to CNPq, for the financial support. The geochemistry laboratory of the University of Brasília is also acknowledged for allowing the analyses of REEs by ICP/AES. 


\section{APPENDIX}

Notation:

$\mathrm{n}$ : normal element

s: spike

$\mathrm{i}$ : individual any isotope

$\mathrm{j}$ : reference isotope (Nd-146; Sm-152)

$\mathrm{u}$ : primary isotope $(\mathrm{Nd}-150 ; \mathrm{Sm}-149)$

$\mathrm{v}$ : secondary isotope (Nd-144; $\mathrm{Sm}-147)$

A: atomic mass

iA: atomic mass of an isotope

An: atomic mass of a normal element

As: atomic mass of a spike

$\mathrm{W}$ : mass in grams

P: $\mathrm{n}^{\circ}$ of atoms

$\mathrm{C}$ : conc. in $\mathrm{g} / \mathrm{mL}$

$\mathrm{F}$ : atomic fraction

Condensed Notation:

$\mathrm{R}^{S}$ : ratio of the spike

$\mathrm{R}^{N}$ : ratio of the normal element

$\mathrm{R}^{M}$ : mix (spike + normal)

$\Delta$ : difference among atomic mass of $\Delta=\mathrm{uA}-\mathrm{jA} ; \Delta=\mathrm{vA}-\mathrm{jA} ; \Delta=\mathrm{iA}-\mathrm{jA}$

TABLE I

Isotopic ratios used for isotope dilution calculations in this study

\begin{tabular}{c|c|c}
\hline Number & Isotopic ratio $\mathrm{Nd}$ & Isotopic ratio $\mathrm{Sm}$ \\
\hline 1 & $150 / 146$ & $149 / 152$ \\
2 & $144 / 146$ & $147 / 152$ \\
3 & $143 / 146$ & \\
\hline
\end{tabular}

i. Calculation of the Atomic Fraction:

$$
i F=\frac{i / j}{\sum_{i} \frac{i}{j}}
$$

2. Representation of the Calculation of the Atomic Mass: 


$$
A=\frac{\sum_{i}(i / j \times i A)}{\sum_{i} \frac{i}{j}}
$$

\section{Calculation of the Concentrations:}

no. of moles $=$ mass of the element $/ \mathrm{A}$

mass of the element $=\mathrm{C}(\mu \mathrm{g} / \mathrm{g}) \times \mathrm{W}$ (mass in $\mathrm{g})$

$$
\frac{C_{n}}{C_{S}} \times \frac{W_{n}}{W_{S}} \times \frac{A_{S}}{A_{n}} \times \frac{j F_{n}}{j F_{S}}=\frac{S_{1}-T_{1}}{T_{1}-N_{1}}
$$

Using the equations (1) and (2) and simplifying the equation above and rearranging for $\mathrm{Cn}(\mu \mathrm{g} / \mathrm{g})$ :

$$
C_{n}=C_{S} \times \frac{W_{S}}{W_{n}} \times \frac{\sum_{i}\left(\frac{i}{j} n \times i A\right)}{\sum_{i}\left(\frac{i}{j} S \times i A\right)} \times \frac{S_{1}-T_{1}}{T_{1}-N_{1}}
$$

\section{Calculation of $\mathrm{Nd}$ Concentration}

Using the equations mentioned, for a mixed spike of $\mathrm{Sm}$ and $\mathrm{Nd}$ enriched in ${ }^{150} \mathrm{Nd}$ (used in the laboratory of geochronology of UnB), we have:

$$
N d(\mu g / g)=\frac{Z_{1} \times C_{S} \times P_{S} \times P . A .}{A \times P_{a}}
$$

where:

$C_{S}=$ concentration ${ }^{150} \mathrm{Nd}$ in the spike $=0.01691492 \mu \mathrm{mols} / \mathrm{g}$

$P . A .=$ atomic mass of $\mathrm{Nd}(144.24 \mathrm{~mol} / \mathrm{g})$

$A=$ natural abundance of ${ }^{150} \mathrm{Nd}=5.6251 \%$ (Russ et al. 1971 and Wasserburg et al. 1981 )

$Z_{1}=\frac{R_{S}-R_{M}}{R_{M}-R_{n}}$

where:

$R_{M}=(146 / 150) \mathrm{m}=$ measured in the spectrometer and corrected for mass fractionation.

$R_{S}=(146 / 150)$ of the spike $=0.00464026$ (calculated from Table II)

$R_{n}=(146 / 150)$ natural $=3.05352835$ (calculated from Table I - Wasserburg et al . 1981)

\section{Calculation of Sm Concentration}

For a mixed spike of $\mathrm{Sm}$ and $\mathrm{Nd}$ enriched in ${ }^{149} \mathrm{Sm}$ :

$$
\operatorname{Sm}(\mu g / g)=\frac{Z_{2} \times C_{S} \times P_{S} \times P . A .}{A \times P_{a}}
$$

where: 
$R_{M}=(147 / 149)$ measured in the spectrometer and corrected for mass fractionation

$R_{S}=(147 / 149)$ in the spike $=0.0033163$ (calculated from Table V)

$R_{n}=(147 / 149)$ natural $=1.088396$ (calculated from Table IV - Wasserburg et al. 1981)

$C_{S}=$ concentration of the ${ }^{149} \mathrm{Sm}$ in the spike $=0.01334888 \mu \mathrm{mols} / \mathrm{g}$

$P . A .=150.35 \mathrm{~mol} / \mathrm{g}$

$A=$ natural abundance of the ${ }^{149} \mathrm{Sm}=13.8504 \%$

\section{Correction for Mass Fractionation}

Thermal ionisation sources, involving the evaporation of the sample starting from a warm filament is subject to the effect of mass fractionation (Potts 1987).

The exact mathematical form of the fractionation law, that describes the instrumental mass fractionation by thermal ionisation is not very well known. The isotope chosen for the correction of the mass fractionation should have great mass difference and their ratio should be also relatively a close to the unit to minimize uncertainties. For $\mathrm{Nd}$ the best choice is ${ }^{150} \mathrm{Nd} /{ }^{142} \mathrm{Nd}$ and the second best is ${ }^{146} \mathrm{Nd} /{ }^{142} \mathrm{Nd}$ (Wasserburg et al. 1981). The factor of fractionation of the isotope of $\mathrm{Nd}$ for unit of atomic mass, it is defined as (Wasserburg et al. 1981):

$$
\begin{array}{rlrl}
\alpha_{L}(u, v) & =\frac{\left[\left(R_{u v}^{N} / R_{u v}^{M}\right)-1\right]}{m_{u v}} & \text { (Linear law) } \\
\alpha_{p}(u, v) & =\left[R_{u v}^{N} / R_{u v}^{M}\right]^{\frac{1}{m_{u v}}}-1 & \text { (Power law) } \\
\alpha_{E}(u, v)=\frac{\ln \left[R_{u v}^{N} / R_{u v}^{M}\right]}{m_{j} \ln \left[m_{u} / m_{v}\right]} & \text { (Exponential law) }
\end{array}
$$

For cases where fractionation is small, these three different laws supply the same corrected values for the required accuracy. However, for cases in which the fractionation is important, each law will supply a different value for the corrected values depending on the choice of the isotope (u,v) used to calculate the correction.

For $\mathrm{Nd}$ and presumably also for $\mathrm{Sm}$, the law of exponential fractionation seems to be better to correct the instrumental fractionation than the linear or power law. Therefore, the use of linear or power laws can introduce significant errors in the ratio ${ }^{143} \mathrm{Nd} /{ }^{144} \mathrm{Nd}$, and this only happens when running a highly fractional analysis. This effect can be minimised by the choice of a different pair of isotope for the normalisation. When ${ }^{146} \mathrm{Nd} /{ }^{142} \mathrm{Nd}$ is used the effect in ${ }^{143} \mathrm{Nd} /{ }^{144} \mathrm{Nd}$ is insignificant; however, for this normalisation, significant errors can be introduced in ${ }^{150} \mathrm{Nd} /{ }^{144} \mathrm{Nd}$. Also when we compare data from different laboratories that normalise in a different way, the use of the linear and power laws introduce small, but significant errors. If the data collected have a small fractionation $(-0.001<\alpha<+0.001)$, the choice of the fractionation law is not necessary.

The fractionation law was suggested in Russell et al. (1978) for the analysis of Ca and that 
also used the Rayleigh fractionation law.

$$
T_{1}=M_{1} \times\left(1+f \times \Delta_{1}\right)
$$

that corresponds to the equation of the Linear law. Solving for f (Boelrijk 1968):

$$
f=\frac{N_{2} \times S_{1}-N_{1} \times S_{2}-M_{2} \times\left(S_{1}-N_{1}\right)+M_{1} \times\left(S_{2}-N_{2}\right)}{M_{2} \times\left(S_{1}-N_{1}\right) \times \Delta_{2}-M_{1} \times\left(S_{2}-N_{2}\right) \times \Delta_{1}}
$$

$\mathrm{Nd}$ isotope - Application in the UnB Laboratory

Reference: 146

Primary: 150

Secondary: 144

TABLE II

Ratio used for fractionation correction.

\begin{tabular}{cc}
\hline Ratios & No. \\
\hline $150 / 146$ & 1 \\
$144 / 146$ & 2 \\
$143 / 146$ & 3 \\
\hline
\end{tabular}

$$
f=\frac{\left\{\left(\frac{144}{146}\right)_{n} \times\left(\frac{150}{146}\right)_{S}-\left(\frac{150}{146}\right)_{n} \times\left(\frac{144}{146}\right)_{S}-\left(\frac{144}{146}\right)_{M}\left[\left(\frac{150}{146}\right)_{S}-\left(\frac{150}{146}\right)_{n}\right]+\left(\frac{150}{146}\right)_{M} \times\left[\left(\frac{144}{146}\right)_{S}-\left(\frac{144}{146}\right)_{n}\right]\right\}}{\left\{\left(\frac{144}{146}\right)_{M} \times\left[\left(\frac{150}{146}\right)_{S}-\left(\frac{150}{146}\right)_{n}\right] \times(144-146)-\left(\frac{150}{146}\right)_{M} \times\left[\left(\frac{144}{146}\right)_{S}-\left(\frac{144}{146}\right)_{n}\right] \times(150-146)\right\}}
$$

Linear law

$$
\begin{aligned}
& T_{3}=M_{3} \times\left(1+f \times \Delta_{3}\right) \\
& T_{2}=M_{2} \times\left(1+f \times \Delta_{2}\right)
\end{aligned}
$$

where:

$$
\begin{aligned}
& M_{3}=143 / 146 \\
& M_{2}=144 / 146 \\
& \Delta_{3}=-3 \\
& \Delta_{2}=-2 \\
& N_{3}=T_{3}+\left(T_{3}-S_{3}\right) \times \frac{\left(T_{1}-N_{1}\right)}{\left(S_{1}-T_{1}\right)} \\
& N_{2}=T_{2}+\left(T_{2}-S_{2}\right) \times \frac{\left(T_{1}-N_{1}\right)}{\left(S_{1}-T_{1}\right)}
\end{aligned}
$$


5. Determination of the Ratio ${ }^{143} \mathrm{Nd} /{ }^{144} \mathrm{Nd}$ :

$$
\frac{{ }^{143} N d}{{ }^{144} N d}=\frac{N_{3}}{N_{2}}=\frac{T_{3}+\left(T_{3}-S_{3}\right)}{T_{2}+\left(T_{2}-S_{2}\right)}
$$

Isotope of Sm - Application in the Laboratory of UnB

Reference: 152

Primary: 149

Secondary: 147

TABLE III

Ratio used for the correction $\mathrm{Sm}$ fractionation

\begin{tabular}{cc}
\hline Ratios & No. \\
\hline $149 / 152$ & 1 \\
$147 / 152$ & 2 \\
\hline
\end{tabular}

$$
f=\frac{\left\{\left(\frac{147}{152}\right)_{n} \times\left(\frac{149}{152}\right)_{S}-\left(\frac{149}{152}\right)_{n} \times\left(\frac{147}{152}\right)_{S}-\left(\frac{147}{152}\right)_{M}\left[\left(\frac{149}{152}\right)_{S}-\left(\frac{149}{152}\right)_{n}\right]+\left(\frac{149}{152}\right)_{M} \times\left[\left(\frac{147}{150}\right)_{S}-\left(\frac{147}{152}\right)_{n}\right]\right\}}{\left\{\left(\frac{147}{152}\right)_{M} \times\left[\left(\frac{149}{152}\right)_{S}-\left(\frac{149}{152}\right)_{n}\right] \times(147-152)-\left(\frac{149}{152}\right)_{M} \times\left[\left(\frac{147}{152}\right)_{S}-\left(\frac{147}{152}\right)_{n}\right] \times(149-152)\right\}}
$$

Linear law

$$
\begin{aligned}
& T_{1}=M_{1} \times\left(1+f \times \Delta_{1}\right) \\
& T_{2}=M_{2} \times\left(1+f \times \Delta_{2}\right)
\end{aligned}
$$

where:

$$
\begin{aligned}
& M_{1}=149 / 152 \text { and } 1=-3 \\
& M_{2}=147 / 152 \text { and } 2=-5
\end{aligned}
$$

The ratio $(147 / 149)_{\text {corrected }}=T_{2} / T_{1}$ (used for calculation of the concentration)

6. Determination of the Ratio ${ }^{147} \mathrm{Sm} /{ }^{144} \mathrm{Nd}$ :

$$
\frac{{ }^{147} S m}{{ }^{144} N d}=\frac{S m(\mu g / g)}{N d(\mu g / g)} \times \frac{A_{N d}}{A_{S m}} \times \frac{147 S m / S m}{{ }^{144} N d / N d}
$$

Using the equation (2):

$$
\begin{aligned}
& A_{N d}=144.23987 \\
& A_{S m}=150.35402
\end{aligned}
$$


Using the values of the tables I, IV and VII:

$$
\begin{aligned}
& { }^{144} \mathrm{Nd} / \mathrm{Nd}=1 /(3.690111-143 / 144) \\
& 143 / 144=0.512 \text { or calculated individually for each sample. } \\
& { }^{147} \mathrm{Sm} / \mathrm{Sm}=0.5651235 / 3.7488669=0.150745
\end{aligned}
$$

\section{TABLES OF USED DATA}

The used data for isotopic dilution calculations and Mass Fractionation, are shown in Tables I to VII.

\section{Calculation of the Amount of Spike to be Mixed with the Sample}

A correctly spiked mixture should have the ${ }^{150} N d /{ }^{146} N d$ ratio close to 1 :

\section{Spike}

Enriched in ${ }^{150} N d=0.01691492 \mathrm{moles} / \mathrm{g}$

${ }^{150} N d=\left[{ }^{150} \mathrm{Ndspike}\right] \mu$ moles atomic $\times \mathrm{A}_{150}$ (mass of the isotope $150 \mathrm{of} \mathrm{Nd}$ ) using data on Table VII:

${ }^{150} N d=0.01691492 \times 149.9209=2.5359 \mu \mathrm{g} / \mathrm{mL}$

\section{Sample}

TABLE I

Isotopic Ratios for natural Nd used for Isotope Dilution Calculations.

\begin{tabular}{lll}
\hline Ratio & Composition* & Composition $^{* *}$ \\
\hline $142 / 146$ & 1.581703 & 1.581712 \\
$143 / 146$ & 0.709269 & 0.710131 \\
$144 / 146$ & 1.385291 & 1.385245 \\
$145 / 146$ & 0.48266 & 0.482642 \\
$146 / 146$ & 1 & 1 \\
$148 / 146$ & 0.334648 & 0.334639 \\
$150 / 146$ & 0.32749 & 0.327479 \\
Total & 5.821061 & 5.821852 \\
\hline *Oxford & & \\
$* *$ Wasserburg et al. 1981. &
\end{tabular}




$$
\begin{aligned}
& \%{ }^{146} N d \text { natural }(\text { Table III })=17.1767 \\
& {\left[{ }^{146} N d\right] \mu g / m L=[N d] \mu g / m L \times 17.1767 / 145.913126}
\end{aligned}
$$

Factor of Proportion (f) $=\left[{ }^{150} \mathrm{Ndspike}\right] \mu \mathrm{g} / \mathrm{mL} /\left[{ }^{146} \mathrm{Ndamostra}\right] \mu \mathrm{g} / \mathrm{mL}$

The amount of spike $P_{S}(m g)$ is:

$$
\begin{aligned}
& P a=f \times P s \\
& P a=(21.5420 /[N d]) \times P s
\end{aligned}
$$

where, $P a=$ weight of the sample (mg) and $P s=$ weight of the spike (mg).

TABLE II

Isotopic Ratios for Nd in mixed Spike, calibrated against with the Blankwash-Tech and BCR-1 rock standards

\begin{tabular}{lll}
\hline Ratio & ${ }^{*}$ Composition & Error $( \pm)$ \\
\hline $150 / 144$ & 196.278416 & 0.01443186 \\
$142 / 144$ & 0.833347772 & $1.9776 .10^{-5}$ \\
$143 / 144$ & 0.49491642 & $8.5537 .10^{-6}$ \\
$146 / 144$ & 0.91078328 & $3.0677 .10^{-5}$ \\
$148 / 144$ & 0.73598967 & $3.5142 .10^{-5}$ \\
$145 / 144$ & 0.43648743 & $1.1085 .10^{-5}$ \\
\hline
\end{tabular}

${ }^{*}$ Spike previously calibrated in the laboratory of Montreal.

TABLE III

Isotopic Abundance for Nd (\%)

\begin{tabular}{lll}
\hline Isotopic & ${ }^{* *}$ Spike & Natural $^{*}$ \\
\hline 142 & 0.415241 & 27.1686 \\
143 & 0.24667 & 12.1977 \\
144 & 0.498281 & 23.7940 \\
145 & 0.217493 & 8.2902 \\
146 & 0.453826 & 17.1767 \\
148 & 0.366730 & 5.7480 \\
150 & 97.801821 & 5.6250 \\
Total & 99.999999 & 100.0001 \\
\hline
\end{tabular}

*Wasserburg et al. 1981

** Montreal. 
TABLE IV

Isotopic Ratio for natural Sm used in the Isotopic Dilution

\begin{tabular}{lll}
\hline Ratio & Composition* & Composition** $^{*}$ \\
\hline $144 / 152$ & 0.1164211 & 0.1164212 \\
$147 / 152$ & 0.5651235 & 0.5651235 \\
$148 / 152$ & 0.4230413 & 0.4230413 \\
$149 / 152$ & 0.519226 & 0.5192261 \\
$150 / 152$ & 0.2768503 & 0.2768391 \\
$152 / 152$ & 1 & 1 \\
$154 / 152$ & 0.8482157 & 0.8482157 \\
Total & 3.7488779 & 3.7488669 \\
\hline$*$ Oxford. & & \\
$* *$ Wasserburg et al. 1981. &
\end{tabular}

TABLE V

Isotopic Ratio for natural Nd in mixed Spike, calibrated using Blankwash-tech and BCR-1 rock standards.

\begin{tabular}{lll}
\hline Ratio & ${ }^{*}$ Composition & Error $( \pm)$ \\
\hline $149 / 152$ & 145.301196 & 0.00765741 \\
$147 / 152$ & 0.4818679 & $3.65 .10-5$ \\
$150 / 152$ & 0.81790385 & $3.5771 .10-5$ \\
$148 / 152$ & 0.76123316 & $5.3087 .10-5$ \\
$144 / 152$ & 0.04911417 & $2.0569 .10-5$ \\
$154 / 152$ & 0.48525055 & $1.633 .10-5$ \\
\hline
\end{tabular}

*Montreal.

\section{REFERENCES}

BoELRIJK NAIM. 1968. A general formula for "double" isotope dilution analysis. Chem Geol 3: 323-325.

Cassidy RM \& Chauvel C. 1989. Modern liquid chromatographic techniques for the separation of Nd and $\mathrm{Sr}$ for isotopic analyses. Chem Geol 74: 189-200.

Chavagnac V \& Jahn B. 1996. Coesite-bearing eclogites from the Bixiling Complex, Dabie Mountains, China: Sm-Nd ages, geochemical characteristics and tectonic implications. Chem Geol 133: 29-51.

DePaolo DJ. 1981. Neodymium isotopes in the Colorado front range and crust-mantle evolution in the 
TABLE VI

Isotopic Abundance for $\mathrm{Sm}(\%)$

\begin{tabular}{lll}
\hline Isotope & ${ }^{* *}$ Spike & Normal $^{*}$ \\
\hline 144 & 0.032985 & 3.1055 \\
147 & 0.323626 & 15.0745 \\
148 & 0.51125 & 11.2845 \\
149 & 97.585324 & 13.8502 \\
150 & 0.54931 & 7.3846 \\
152 & 0.671607 & 26.6747 \\
154 & 0.325898 & 22.6259 \\
Total & 100.032985 & 99.9999 \\
\hline
\end{tabular}

*Wasserburg et al. 1981.

*Montreal.

TABLE VII

Atomic mass (Wapstra \& Bos 1977)

\begin{tabular}{llll}
\hline Isotope & $\mathrm{Nd}$ & Isotope & $\mathrm{Sm}$ \\
\hline 142 & 141.907731 & 144 & 143.912009 \\
143 & 142.909823 & 147 & 146.914907 \\
144 & 143.910096 & 148 & 147.914832 \\
145 & 144.912582 & 149 & 148.917193 \\
146 & 145.913126 & 150 & 149.917285 \\
148 & 147.916901 & 152 & 151.919741 \\
150 & 149.920900 & 154 & 153.922218 \\
\hline
\end{tabular}

Proterozoic. Nature 291: 193-196.

Dosso L \& Murthy VR. 1980. A Nd isotope study of the Kerguelen islands: inferences on enriched oceanic mantle soucers. Earth Planet Sci Lett 48: 268-276.

Eugster O, Tera F, Bernett DS \& Wasserburgh GJ. 1970. Isotopic Composition of Gd and NeutronCapture Effects in some Meteorites. J Geophys Res 75: 2753-2768.

Getty SR, Selverstone J, Wernicke BP, Jacobsen SB, Aliberti E \& Lux DR. 1993. Sm-Nd dating of multiple garnet growth events in an arc-continent collision zone, northwestern U.S. Cordillera. Contrib Mineral Petrol 115: 45-57.

Gladney ES, Burns CE \& RoelandTs I. 1983. 1982 copilation of elemental concentrations in eleven United States Geological survey rock standards. Geostand Newslett 7: 3-226.

Govindaraju K. 1994. Compilation of working values and sample description for 383 geostandards. 
Geostand Newslett (special Issue), 18: 1-158.

Hemning SR, McLennan SM \& Hanson GN. 1995. Geochemical and Nd/Pb isotopic evidence of the Early Proterozoic Virginia Formation, Minnesota. Implications for the Tectonic Setting of the Animikie Basin. J Geol 103: 147-168.

Hooker PJ, O’Nions RK \& PANKhurst RJ. 1975. Determination of rare-earth elements in USGS standard rocks by mixed-solvente ion exchange and mass-spectrometric isotope dilution. Chem Geol 16: 189196.

Ito E, White WM \& Göpel C. 1987. The O, Sr, Nd and Pb isotope geochemistry of MORB. Chem Geol 62: $157-176$.

Kawashita K, Diaz M \& Tassinari CCG. 1991. $3^{\circ}$ Congresso de Geoquímica. S. Paulo. vol II: 442-446.

Ketelle BH \& Boyd GE. 1951. Further studies of the Ion-Exchange Separation of the rare earths. $J$ Am Chem Soc 73: 1862-1863.

Le Roex AP \& Watkins RT. 1990. Analysis of rare-earth elements in geological samples by gradient chromatography: An alternative to ICP and INAA. Chem Geol 88: 151-162.

LI X. 1994. A comprehensive U-Pb, Sm-Nd, Rb-Sr and ${ }^{40} \mathrm{Ar}-{ }^{39} \mathrm{Ar}$ geochronological study on Guidong Granodiorite, southeast China: records of multiple tectothermal events in a single pluton. Chem Geol 115: $283-295$.

Lugmair GW \& MARTI K. 1978. Lunar inicial ${ }^{143} \mathrm{Nd} /{ }^{144} \mathrm{Nd}$ : Differencial evolution of the lunar crust and mantle. Earth Plan Sci Lett 39: 349-357.

Мавоко MAH \& NAKAmURA E. 1995. Sm-Nd garnet ages from the Uluguru granulite complex of Eastern Tanzania: further evidence for post-metamorphic slow cooling in the Mozambique belt. Precamb Res 74: 195-202.

Mukasa SB, Flower MFJ \& Miklius A. 1994. The Nd-, Sr- and Pb-isotopic character of lavas from Taal, Laguna de Bay and Arayat volcanoes, southwestern Luzon, Philippines: implications for arc magma petrogenesis. Tectonophysics 235: 205-221.

Nakamura N. 1974. Determination of REE, Ba, Fe, Mg, Na and K in carbonaceous and ordinary chondrites. Geochim Cosmochim Acta 38: 757-775.

O'Nions RK, Hamilton PJ \& Evensen NM. 1977. Variations in ${ }^{143} \mathrm{Nd} /{ }^{144} \mathrm{Nd}$ and ${ }^{87} \mathrm{Sr} /{ }^{86} \mathrm{Sr}$ ratios in oceanic basalts. Earth Plan Sci Lett 34: 13-22.

Patchett PJ \& Ruiz J. 1987. Nd isotopic ages of crust formation and metamorphism in the Precambrian of eastern and southern Mexico. Contrib Mineral Petrol 96: 523-528.

PotTs PJ. 1987. Handbook of Silicate Analysis. London. Blakie. 622p.

RehKamper M, Gartner M, Gale SJG \& Goldstein SL. 1996. Separation of Ce from other Rare-earth Elements with Application to Sm-Nd and La-Ce Chronometry. Chem Geol 129: 201-208.

Richard P, Shimizu N \& Allègre CJ. 1976. ${ }^{143}$ Nd/ ${ }^{146}$ Nd A Natural Tracer: An Application to Oceanic 
Basalts. Earth Plan Sci Lett 31: 269-278.

Russ GP, Burnett DS, Lingeufelter RE \& Wasserburg GJ. 1971. Neutron capture on ${ }^{149}$ Sm in lunar samples. Earth Plan Sci Lett 13: 53-60.

Russell WA, Papanastassiou DA \& Tombrello TA. 1978. Ca isotope fractionation on the Earth and other solar systems materials. Geochim Cosmochim Acta 42: 1075-1090.

SATo K. 1998. Evolução crustal da plataforma sul americana, com base na geoquímica isotópica Sm-Nd. São Paulo. 297p. (Tese de Doutorado. Instituto de Geociências da USP).

SORENSEN HS \& Wilson R. 1995. A strontium and neodymium isotopic investigation of the FongenHyllingen layered intrusion, Norway. J Petrol 36(1): 161-187.

Stray H \& Dahlgren S. 1995. A combined classical ion-exchange and HPIC procedure for the separation of $\mathrm{Nd}$ and $\mathrm{Sm}$ for isotopic analysis of geological samples. Chem Geol 125: 233-238.

Sun S, Warren RG \& SHAw RD. 1995. Nd isotope study of granites from the Arunta Inlier, central Australia: constraints on geological models and limitation of the method. Precamb Res 71: 301-314.

ThiRwall MF. 1982. A triple-filament method for rapid and precise analysis of rare-earth elements by isotope dilution. Chem Geol 35: 155-166.

ThIRWALL MF. 1991. Long-term reproducibility of multicollector $\mathrm{Sr}$ and $\mathrm{Nd}$ isotope ratio analysis. Chem Geol 94: 85-104.

Tourpin S, Gruau G, Blais S \& Fourcade S. 1991. Resetting of REE, and Nd and Sr isotopes during carbonization of a komatiite flow from Finland. Chem Geol 90: 15-29.

VERMA SP. 1991. Usefulness of liquid chromatography for determination of thirtheen rare-elements in rocks and minerals. Lanthanide Actinide Res 3: 237-257.

Wapstra AH \& Box K. 1977. The 1977 atomic mass evaluation in four parts; Part I. Atomic mass table. At Data Nucl Data Tables 19: 177-214.

Wasserburg GJ, Jacobsen SB, DePaolo DJ, McCulloch MT \& Wen T. 1981. Precise determination of $\mathrm{Sm} / \mathrm{Nd}$ ratios, $\mathrm{Sm}$ and $\mathrm{Nd}$ isotopic abundances in standard solutions. Geochim Cosmochim Acta 45: 2311-2323.

White WM \& Patchett J. 1984. Hf-Nd-Sr isotopes and incompatible element abundances in island arcs: implications for magma origins and crust-mantle evolution. Earth Plan Sci Lett 67: 167-185.

Whitehouse MJ. 1989. Sm-Nd Evidence for Diachronous Crustal Accretion in the Lewisian Complex of Northwest Scotland. Tectonophysics 161: 245-256.

Zhao J \& McCulloch MT. 1995. Geochemical and Nd isotopic systematics of granites from the Arunta Inlier, central Australia: implications for Proterozoic crustal evolution. Precamb Res 71: 265-299. 